\title{
Erratum to: Minimally invasive PLIF with divergent, cortical trajectory pedicle screws
}

Pedro Berjano - Marco Damilano - Maryem Ismael •

Carlo Formica · Diego Garbossa

Published online: 25 February 2015

(c) Springer-Verlag Berlin Heidelberg 2015

Erratum to: Eur Spine J

DOI 10.1007/s00586-015-3802-8

There was an error in the authors name of the article.

The correct name is: Diego Garbossa.

The online version of the original article can be found under doi:10.1007/s00586-015-3802-8.

P. Berjano $(\varangle) \cdot$ M. Damilano · M. Ismael · C. Formica ·

D. Garbossa

IRCCS Istituto Ortopedico Galeazzi, Milan, Italy

e-mail: pberjano@gmail.com 